\title{
JOURNAL.RU
}

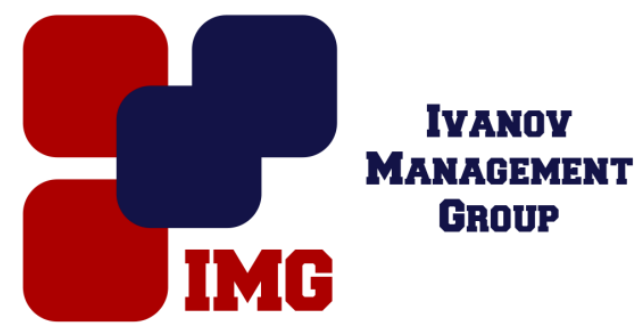

Буранова М.О.

Карии, Узбекистан

doi: 10.18411/1j-30-06-2017-03

idsp 000001:1j-30-06-2017-03

\section{Некоторые геофиты Дехканабадского района}

\section{Аннотация}

В статье приведены данные о некоторых видах геофитов, определённых в предгорной зоне Дехканабадского района Кашкадарьинской области, а также их хозяйственное значение.

Ключевые слова: геофиты, корневищные, луковичные, корневые и клубневыегеофиты, эфемероиды.

Дехканабадский район расположен на юге Республики Узбекистан в Кашкадарьинской области. Здесь горы Гиссарского хребта создают маленькую долину, вследствие чего образуется своего рода микроклимат, не повторяющийся на Земном шаре. Это способствует возникновению растительного покрова, значительно различающегося от других близлежащих территорий.

Геофиты этожизненная форма растений, почки возобновления и окончания побегов у которых переносят неблагоприятный период в почве.

В наших экспедициях по Дехканабадскому району, проведённых в период с 2010 по 2015 годы, изучался растительный покров отдельных территорий на наличие геофитов. В результате определили 28 видов геофитов из 16 родов и 12 семейств. 
Геофиты Дехканабадского района

\begin{tabular}{|c|c|c|c|c|}
\hline № & Семейство & Род & Вид & Тип \\
\hline 1 & \multirow{3}{*}{ Amarillidaceae } & \multirow{3}{*}{ Allium } & A. drepanophyllum Vved. & Луковичный \\
\hline 2 & & & A. griffithianum Boiss. & Луковичный \\
\hline 3 & & & A. gypsaceum M. Pop \& Vved. & Луковичный \\
\hline 4 & \multirow{2}{*}{ Apiaceae } & \multirow{2}{*}{ Ferula } & F.assa-foetida L. & Корневой \\
\hline 5 & & & F.sumbul K. Pop. & Корневой \\
\hline 6 & Asphodelaceae & Eremurus & Eremurus luteus Baker & Корневищный \\
\hline 7 & \multirow{5}{*}{ Asteraceae } & \multirow{4}{*}{ Achillea } & A.filipendulina Lam & Корневищный \\
\hline 8 & & & A.millefolium L. & Корневищный \\
\hline 9 & & & A.biebersteinii C. A. Fan & Корневищный \\
\hline 10 & & & A.wilhelmsii C. Koch. & Корневищный \\
\hline 11 & & Cichorium & C.intybus L. & Корневой \\
\hline 12 & \multirow{2}{*}{ Cyperaceae } & \multirow{2}{*}{ Carex } & C. pachystylis J. Gay & Корневищный \\
\hline 13 & & & C. physodes Bieb. & Корневищный \\
\hline 14 & Fabaceae & Glycyrrhiza & Glycyrrhizaglabra L. & Корневищный \\
\hline 15 & \multirow{2}{*}{ Hypericaceae } & \multirow{2}{*}{ Hypericum } & H.perforatum L. & Корневищный \\
\hline 16 & & & H.scabrum L. & Корневищный \\
\hline 17 & Iridaceae & Crocus & Crocus korolkowii Rgl et Maw & Клубневый \\
\hline 18 & Ixioliriaceae & Ixiolirion & $\begin{array}{l}\text { I. tataricum (Pall.) Schult. \& } \\
\text { Schult. fil. }\end{array}$ & Клубневый \\
\hline 19 & \multirow{5}{*}{ Liliaceae } & \multirow{3}{*}{ Gagea } & G. hissarica Lipsky & Луковичный \\
\hline 20 & & & G.stipitata & Луковичный \\
\hline 21 & & & G.turkestanicaPasher & Луковичный \\
\hline 22 & & \multirow{2}{*}{ Tulipa } & T. ingens Th. Hoog & Луковичный \\
\hline 23 & & & T. turkestanica (Regel) Regel & Луковичный \\
\hline 24 & \multirow{4}{*}{ Poaceae } & Poa & P. bulbosa L. & Корневой \\
\hline 25 & & \multirow{2}{*}{ Agropyron } & A.repens (L) P. Beause & Корневищный \\
\hline 26 & & & A.trichophorum (Link) R. & Корневищный \\
\hline 27 & & Cynodon & C.dactylon (L) Pers & Корневищный \\
\hline 28 & Scrophulariaceae & Dodartia & D.orientalis L. & Корневой \\
\hline
\end{tabular}

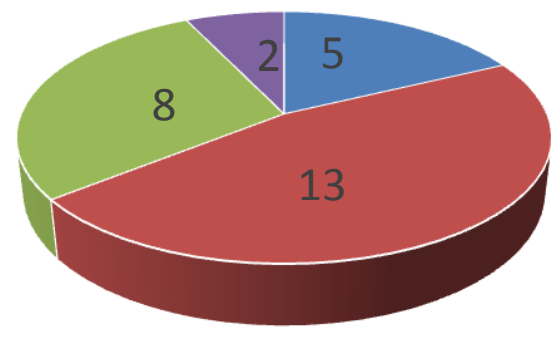

- Корневые

- Луковичные
Корневищные

- Клубневые

Рис. 1. Количество видов геофитовв районе Дехканабад.

Из рис. 1 становится ясно, что большинство видов это корневищные и луковичные геофиты эфемероидного типа, приспособленные для засушливых регионов. 
Таблийа 2

Хозяйственное значение геофитов Дехканабадского района

\begin{tabular}{|c|c|c|c|c|c|c|}
\hline № & Род & Вид & $\begin{array}{c}\text { Лекарст- } \\
\text { венные }\end{array}$ & Фураж & $\begin{array}{c}\text { Пище- } \\
\text { вые }\end{array}$ & $\begin{array}{l}\text { Декора- } \\
\text { тивные }\end{array}$ \\
\hline 1 & \multirow{3}{*}{ Allium } & A. drepanophyllum Vved. & & & + & + \\
\hline 2 & & A. griffithianum Boiss. & & & + & + \\
\hline 3 & & $\begin{array}{l}\text { A. gypsaceum M. Pop \& } \\
\text { Vved. }\end{array}$ & & & + & + \\
\hline 4 & \multirow{2}{*}{ Ferula } & F.assa-foetida L. & + & & & \\
\hline 5 & & F.sumbul K. Pop. & + & & & \\
\hline 6 & Eremurus & Eremurus luteus Baker & + & & & + \\
\hline 7 & \multirow{4}{*}{ Achillea } & A.filipendulina Lam & + & & & \\
\hline 8 & & A.millefolium L. & + & & & \\
\hline 9 & & A.biebersteinii C. A. Fan & + & & & \\
\hline 10 & & A.wilhelmsii C. Koch. & + & & & \\
\hline 11 & Cichorium & C.intybus L. & + & & & \\
\hline 12 & \multirow{2}{*}{ Carex } & C. pachystylis J. Gay & & + & & \\
\hline 13 & & C. physodes Bieb. & & + & & \\
\hline 14 & Glycyrrhiza & Glycyrrhizaglabra L. & + & & & \\
\hline 15 & \multirow{2}{*}{ Hypericum } & H.perforatum L. & + & & & \\
\hline 16 & & H.scabrum L. & + & & & \\
\hline 17 & Crocus & $\begin{array}{c}\text { Crocus korolkowii Rgl et } \\
\text { Maw }\end{array}$ & + & & & + \\
\hline 18 & Ixiolirion & $\begin{array}{l}\text { I. tataricum (Pall.) Schult. \& } \\
\text { Schult. fil. }\end{array}$ & & & & + \\
\hline 19 & \multirow{3}{*}{ Gagea } & G. hissarica Lipsky & & + & & + \\
\hline 20 & & G.stipitata & & + & & + \\
\hline 21 & & G.turkestanicaPasher & & + & & + \\
\hline 22 & \multirow[b]{2}{*}{ Tulipa } & T. ingens Th. Hoog & & & & + \\
\hline 23 & & $\begin{array}{l}\text { T. turkestanica (Regel) } \\
\text { Regel }\end{array}$ & & & & + \\
\hline 24 & Poa & P. bulbosa L. & & + & & \\
\hline 25 & \multirow{2}{*}{ Agropyron } & A.repens (L) P. Beause & & + & & \\
\hline 26 & & A.trichophorum (Link) R. & & + & & \\
\hline 27 & Cynodon & C.dactylon (L) Pers & & + & & \\
\hline 28 & Dodartia & D.orientalis L. & + & & + & \\
\hline
\end{tabular}




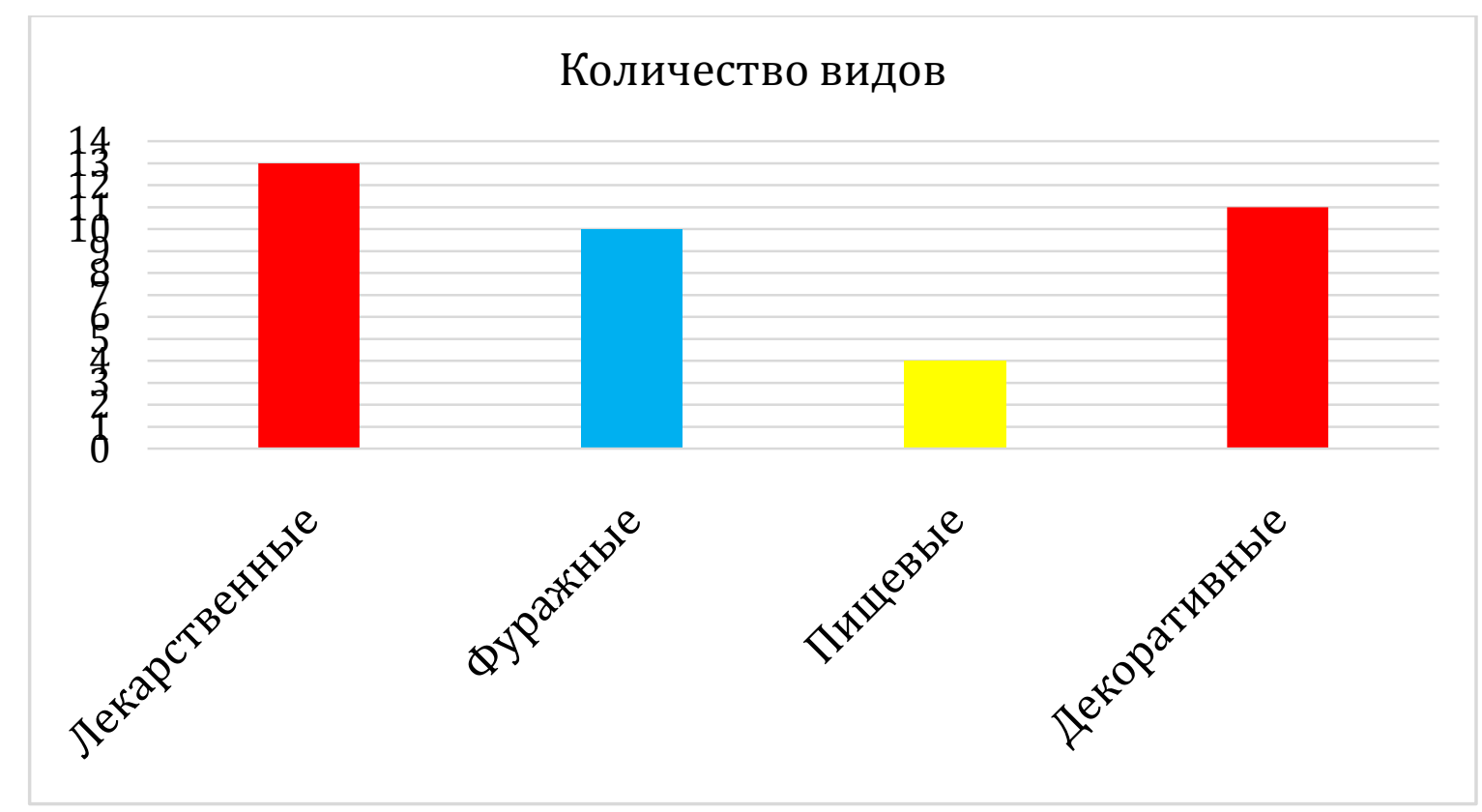

Рис. 2. Хозяйственное значение геофитов.

Среди лекарственных геофитов в данное время наиболее ценными являются F. assa-foetidaL. и F. sumbulK. Рор. Большое количество местных жителей собирают их смолу, которая экспортируется в Афганистан и Индию. Среди декоративных T. ingens Th. Hoog внесён в Красную Книгу Республики Узбекистан.

Из 28 видов только 4 вида являются пищевыми, это виды луковичных и додарция восточная.

\section{Литература}

1. Pratov O‘.P., Nabiyev M.M. O'zbekiston yuksak o'simliklarining zamonaviy tizimi. Toshkent, 2007. - $64 \mathrm{~b}$.

2. Коллектив. Флора Узбекистана. I-VI т. - Ташкент, 1941-1962 г.

3. Черепанов С.К. Сосудистые растения России и сопредельных государств (в пределах бывшего СССР). - Санкт-Петербург, 1995. — 991 с. 